DOI: 10.17805/trudy.2015.5.6

\title{
ДИПЛОМАТИЧЕСКИЕ УЧЕБНЫЕ ЗАВЕДЕНИЯ В РОССИИ (ИСТОРИЧЕСКИЙ ОЧЕРК)
}

\author{
И. В. Сидоров \\ (Московский гуманитарный университет)
}

Аннотация: В статье по разнообразным источникам прослеживается история специализированного дипломатического образования в России. При этом автор стремился выявить в этом процессе идейно-ценностные установки российской власти в отношении внешней политики страны и тех, кто ее осуществлял в разные эпохи, успехи и неудачи российского образования в целом.

Ключевые слова: Россия; дипломатия; история дипломатии; дипломатическое образование; высшее образование; история России

\section{DIPLOMATIC EDUCATIONAL INSTITUTIONS IN RUSSIA (A HISTORICAL OVERVIEW)}

\author{
I. V. Sidorov \\ (Moscow University for the Humanities)
}

\begin{abstract}
Making use of a variety of sources, the article traces the history of professional education in diplomacy in Russia. In the course of our analysis, we have sought to identify the ideological guidelines of the Russian authorities concerning the nation's foreign policy and those who implemented it over time. A special focus is made on the successes and failures of Russian education in general.

Keywords: Russia; diplomacy; history of diplomacy; diplomatic education; higher education; history of Russia
\end{abstract}

На многие проблемы современной дипломатии, в том числе и кадровые, сегодня можно и нужно искать ответы в историческом опыте. Это делает заявленную тематику статьи подлинно актуальной. Эту тему не обходят вниманием признанные российские теоретики и практики отрасли - А. И. Кузнецов, А. В. Торкунов, Е. В. Воевода и др. Значимой она является и для тех, кто делает лишь первые шаги в дипломатическую профессию. Представляется, что основательная разработка научной проблемы «История развития системы подготовки дипломатических кадров России» с непременным включением ее достижений в учебные программы, учебники и курсы лекций послужит воспитанию и развитию патриотизма у молодых международников, подготовит их к восприятию корпоративно- 
го духа дипслужбы, привьет интерес к познанию исторических сторон тех проблем, что встретятся им в процессе трудовой деятельности.

Представленная вниманию читателя статья основана на оригинальных документальных материалах Архива внешней политики Российской империи (АВПРИ) Историко-документального департамента МИД Российской Федерации, где автор имел возможность пройти производственную практику.

В историческом плане специализированное дипломатическое образование не может быть рассмотрено в отрыве от российского образования и общества в целом, поскольку хотя и являет собой его «огороженную» в известной степени ведомственностью часть, однако вместе с тем и одну из наиболее ярких его частей, традиционно элитных и передовых. Долгое время ни о какой специализации в образовании речи не шло вообще. Однако формирование личности специалиста в области внешней политики и его взаимодействие с обществом (выражение и реализация интересов, влияние на государственную политику и пр.) являются отражением уровня крепости и мощи государства и гражданского общества.

Поэтому проблематика темы в методологическом плане может рассматриваться через призму проблемы взаимных отношений личности и общества, которая принадлежит к наиболее сложным в области гуманитарного знания, особенно если рассматривать ее с нормативной, деонтологической точки зрения, то есть интересоваться этими отношениями со стороны желательности, целесообразности и справедливости, для них возможных. Чем выше находится общество в культурном и социальном отношениях, тем более оно помогает проявлению индивидуальной жизни и деятельности, чтобы из отдельного индивидуума, из представителя культурной группы, из члена общественного организма формировалась личность как развитое $Я$ со своими оригинальными мыслями, чувствами и волей.

Но и с теоретической точки зрения, имеющей в виду надлежащее понимание того, что есть, как оно есть, то есть понимание объективной действительности, вопрос о положении личности в обществе и о взаимных их отношениях получает различную постановку, в зависимости от того, как рассматривается личность по отношению к государству: в качестве подданного, гражданина либо должностного лица; по отношению к праву как его субъект или объект; по отношению, наконец, к народному хозяйству как производитель либо потребитель, каковы бывают различные положения людей в отдельных сторонах общественной структуры и какое значение имеет деятельность этих людей в осуществлении общественных целей.

Это верно и для тех случаев, когда отдельные лица действуют от имени целого общества как носители публичной власти и ее агенты. Пусть 
они в этом отношении уподобляются органам, исполняющим определенные функции в общественном организме, но эти органы власти - такие же человеческие существа, такие же личности, как и подвластные им члены общества. Какой-то отделенной от тех или других личностей безличной власти как чего-то неоднородного с подчиняющимися ей людьми не существует: носителями, представителями, агентами органов власти бывают только определенные личности.

Духовная культура данного общества и его экономические, юридические и политические формы являются условиями, воздействующими на деятельность каждой отдельной личности. В свою очередь, эти над-органические условия сами изменяются в зависимости не только от физических и биологических причин, но и от деятельности людей. По отношению к историческому процессу проблема личности и общества определяется как проблема взаимоотношений личности и надорганической (культурно-социальной, или духовно-общественной) среды. Разобраться во всех этих методологических сложностях позволяет наследие русской исторической школы второй половины XIX в. (см.: Васильев, 2006, 2009ab, 2010ab, 2011ab, 2012).

В течение многих столетий вообще не ставился вопрос о профильном органе внешних связей на Руси. Высшего образования наша страна не ведала более восьми столетий, включая период, когда Посольский приказ и отчасти некоторые другие приказы уже занимались проблемами дипломатии - в то время как первый европейский университет был открыт в Византии еще в IX веке.

Поначалу потребность элиты (чьей исключительной привилегией было занятие дипломатией) в знаниях удовлетворяли школы при монастырях и церквях, причем кроме обучения грамоте там преподавались также богословие, грамматика, диалектика (начала философии, включавшей тогда в себя и элементы естественнонаучного знания), риторика. Кроме того, именно элите были доступны достижения книжности. В профессиональном плане феодалы - господствующий класс той эпохи - были универсалами: они могли в одном случае руководить битвой, в другом - возглавлять делегацию послов, обсуждавших ее исход. Необходимые для этого навыки приобретались непосредственно «на рабочем месте» - на службе государевой, которую несли с юных лет. Годы упадка русской культуры и государственности, вызванные имевшей хозяйственные и политические корни раздробленностью и последовавшим ордынским игом, законсервировали такое состояние.

Своего рода «технократы» - профессионалы русской государственной службы появились, по-видимому, в пору ее становления (реформа системы управления была начата Иваном III на рубеже XV-XVI вв.): так, в 
работе Боярской думы кроме собственно бояр и дворян принимали участие дьяки - люди не столь знатные, но наиболее компетентные. С появлением приказов, и среди прочих в 1549 г. Посольского (тогда еще не приказа, а «избы»), их таланты получили организационную «оправу». В это же время менялся облик дипломатии, которая претерпела трансформацию от лично-семейного характера к форме особой отдельной институции. С падением Византии на Руси появились своего рода «мэтры» дипломатии - носители царьградской модели внешней политики и опыта Константинополя.

Однако и тогда никакой специфичной учебы не существовало. Так, в ливонской хронике сообщалось об удивлении иностранных послов по поводу эрудиции Ивана Висковатого - первого главы Посольского приказа и... «московита, нигде не учившегося». Попытка же создать университет, предпринятая Борисом Годуновым, окончилась ничем из-за противодействия духовенства (см.: Высшее образование в России ..., 1995: 24).

B XVII в. приказная система вошла в пору расцвета. Ее основным костяком и рабочей силой были подьячие - по социальному составу дети «служивых» и духовенства. Роль Посольского приказа выросла с повышением в середине столетия чина его главы до боярина и ликвида-цией в 1682 г. местничества - т. е. шагом вперед в плане доступности государственного управления не только для аристократов. В этом же столетии учреждались школы при приказах, в т. ч. и Посольском. В 1687 г. был создан первый российский вуз - Славяно-греко-латинская академия, где наряду с религиозными догматами преподавались и различные языки, а один из ее основателей и директоров, Иоанникий Лихуд, сам исполнял по поручению московского царя дипломатические миссии. В отличие от этого учебного заведения носивший более светский характер другой проект Московской Академии, разработанный С. Медведевым, к сожалению, преодолеть исключительно косную социально-культурную среду той поры и диктат церковных деятелей не смог, а потому реальностью так и не стал.

Отметим также, что в штате Посольского приказа в этот период появилась категория «новых неверстаных» (Похлебкин, 1992: 176) подьячих без оплаты труда - молодых чиновников, обучающихся профессии - пока что опять же «без отрыва от производства». По-видимому, именно эту структуру имеют в виду, когда говорят о «Посольской школе» (см.: Высшее образование в России ..., 1995: 27-28), основанной в 1689 г. Ученики ее упражнялись преимущественно в канцелярских науках, улучшая свою грамотность, технику письма, осваивая специфику дипломатической документации. Иностранные языки в программу школы не входили, так как в штате приказа имелось достаточное количество переводчиковиностранцев, а более поздняя попытка подготовить своих «лингвистов» 
осуществлялась вне стен Посольской школы.

В условиях петровской модернизации в России возникали светские учебные заведения (Школа математических и навигацких наук и др.). Впрочем, стремительность и многоплановость перемен, затеянных Петром Великим, не способствовали разделению труда среди царевых слуг. Знатная молодежь, в том числе прошедшая зарубежную школу, занималась, как и сам царь, то кораблестроением, то войной, то делами мира. Однако явные таланты все же постепенно закреплялись за конкретными отраслями, чему не стала исключением и Коллегия иностранных дел новое профильное ведомство России.

Профессиональная подготовка в этот период по-прежнему проводилась в форме ученичества. Приглашались на обучение непосредственно в Коллегию молодые дворяне, а также и дети всех желающих - в кадровой политике Петра I способности ценились выше родовитости. Придать же подготовке дипломатических кадров законченную форму школы не удалось. Ученичество в самих коллегиях было закреплено Табелью о рангах 1722 г., вводившей чин «коллегии юнкера». Будущие дипломаты учились профессии и за рубежом, в статусе «дворян посольства» практикуясь в зарубежных представительствах России на постах секретарей и переводчиков - то есть в качестве младших руководителей и экспертов.

Преемники Петра вернули во главу угла принцип сословности, а не верховенства деловых качеств. Учрежденные в середине XVIII в. заведения - Шляхетский и Пажеский корпуса, ориентированные на госслужбу, были построены в полном соответствии с этим принципом. Важной вехой данного периода стало основание в 1755 г. Московского университета. Важно, что уже тогда идею о замещении государственных постов не иначе как при наличии у кандидата диплома об образовании или же о сдаче экзамена на знание эквивалентной программы курса университета (для получивших образование на дому), предлагал влиятельный покровитель нового вуза И. И. Шувалов (там же: 60), чем предвосхитил предложения знаменитого М.М.Сперанского. Интересно, что на юридическом факультете имелась кафедра «политики» - в современном понимании кафедра истории международных отношений и международного права (там же: 58).

При Екатерине II происходили изменения в институте коллегии юнкеров. Обучение их в коллегиях, наконец, принявшее, судя по тексту манифеста императрицы (Манифест от 15 декабря 1763 г. ..., Электр. ресурс), форму учебных заведений - юнкерских школ - было заменено открытием «классов российского права» в Сухопутном кадетском корпусе и Московском университете. Теперь они должны были заниматься подготовкой российского чиновничества - естественно предположить, что в том числе и в интересах Коллегии иностранных дел. В это же время, 
как следует из архивных документов, имела место практика подготовки переводчиков для внешнеполитического ведомства путем набора учеников, постигавших редкие языки, в том числе и за рубежом, из студентов духовных семинарий (АВПРИ. Ф. «Сношения России с Китаем». Оп. 62/2. Д. 5. Л. 128-129). Уже в следующее правление именно это обстоятельство, в из-вестной степени замедлявшее пополнение штатов дипломатического органа сведущими в языках кадрами, сподвигло одного из коллежских переводчиков, Антона Владыкина, обратиться в Коллегию иностранных дел с прошением предоставить ему на обучение китайскому и маньчжурскому языкам нескольких студентов или писарей того же ведомства. Повидимому, именно эта небольшая ученическая группа именуется «Училищем для обучения восточным языкам» (см.: Похлебкин, 1992: 210). Нельзя не отметить, что, согласно документам, прошение А. Владыкина было удовлетворено и было весьма успешным. Преподавал он трем коллежским актуариусам (должность, аналогичная современному делопроизводителю) китайский и маньчжурский языки, а также российскую грамматику, начала арифметики, краткую российскую историю и сокращенный православный катехизис (АВПРИ. Ф. «Сношения России с Китаем». Оп. 62/2. Д. 5. Л. 183-183об.). Считаем справедливым считать именно этот момент отправной точкой Службы языковой подготовки МИД в противовес принятой сейчас увязке ее с учреждением учебного заведения, открывшегося на четверть века позже.

В начале XIX столетия политика в области образования была противоречивой. Монархическое государство пыталось сохранить контроль над образованием и просвещением, однако при этом он объективно нуждался в самых разнообразных кадрах, как технических, так и административных. Не стала исключением и дипломатическая отрасль. Павел I учредил Дипломатическую школу при Коллегии, имевшую целью подготовить сведущих в языках и «свободных науках» молодых профессионалов. Был проведен первый набор, причем интересно, что итоги экзамена по иностранным языкам выявили неудовлетворительное знание его чиновниками Коллегии - кандидатами на обучение. При Александре I был издан указ о том, что-бы «школу при Коллегии иностранных дел на особенном положении» «в действие не приводить» (АВПРИ. Ф. «Административные дела». Оп. IV. Д. 1. Л. 11). Мотивировать это решение император по неизвестным причинам не пожелал.

Однако потребность в профильном учебном заведении была актуальной, поэтому ею занимался сам министр А. Р. Воронцов, брат которого С. Р. Воронцов, блестящий и известный дипломат, в свое время уже высказывал идею о необходимости открытия дипломатической школы в России (см.: Очерки истории МИД России ... , 2002: 13-14). Помогал А. Р. Воронцо- 
ву его заместитель и будущий преемник А. А. Чарторыйский. Разработка нового проекта Школы была поручена известному немецкому дипломату и ученому-правоведу Г. Мартенсу, задумки которого по ряду причин так и не были воплощены. Не была реализована также идея создания такого учебного подразделения в рамках учреждаемого Санкт-Петербургского университета.

Компенсировать нехватку особого учебного заведения пытались, в частности, организацией специализации в Царскосельском (позднее Александровском) лицее. Так, известно, что А. М. Горчаков (он был в числе первых его воспитанников и окончил лицей вместе с А. С. Пушкиным в 1817 г.) посещал там отдельные специализированные занятия для будущих дипломатов (там же: Л. 116). Выпускником Лицея (1875 г.) был и еще один министр иностранных дел - А. П. Извольский, автор прогрессивного проекта реформы русской дипслужбы начала XX в.

Собственный вуз у Министерства иностранных дел впервые появился только в 1835 г., официальный статус был присвоен решением Государственного совета Учебному отделению восточных языков при Азиатском департаменте (УОВЯ), созданному в 1823 г. (АВПРИ. Ф. «Учебное отделение восточных языков при Азиатском департаменте МИД». Оп. 668. Д. 100. Л. 4-4об.). Характерно, что в этот же год был принят новый университетский Устав, в котором отразилось понимание правительством важности подготовки дипломатических кадров налицо.

Учебно-педагогическая деятельность Отделения освещена в литературе, в т. ч. на основе материалов АВПРИ (см.: Воевода, Электр. ресурс). Следует отметить, что данный вуз был предметом живого и постоянного интереса со стороны руководства внешнеполитического ведомства. И хотя его учебная деятельность не была массовой, качество образования и научная жизнь поддерживались на высоком уровне.

Интересно, что УОВЯ занималось также обучением офицеров на особом Офицерском курсе. А вот широко известный Лазаревский институт восточных языков, хотя и имел в своем составе специальные классы с правами вуза, не давал своим выпускникам права поступать на государственную службу и потому в нашем аспекте проблемы может быть рассмотрен только как промежуточная ступень - многие его питомцы продолжали обучение именно в УОВЯ.

В 1835 г. появилось еще одно учебное заведение, готовившее специалистов в том числе и для государственной дипслужбы - Императорское училище правоведения. И хотя оно относилось к ведению Министерства юстиции, а потому не может быть названо дипломатическим, его выпускники проявили себя и на внешнеполитическом поприще, в частности, Р. Р. Розен был послом в нескольких странах Европы и Азии. 
Введенные в 1859 г. А. М. Горчаковым правила приема на дипломатическую службу требовали наличия у кандидата диплома о высшем образовании (см.: Зонова, 2003: 298). Таким образом, еще одной кузницей дипломатических кадров стали обычные университеты. Петербургский университет, в частности, закончил выдающийся советский дипломат, чья карьера началась еще в царском министерстве иностранных дел, нарком иностранных дел Г. В. Чичерин. Интересно, что требование наличия высшего образования у желающих стать дипломатом было фактически подтверждено и Временным правительством в документах «Временные правила о порядке приема и прохождении службы в Министерстве иностранных дел» (15 сентября 1917 г.) (см.: Министерство иностранных дел России ... , 2014: 773-774) и Представлении МИД Временном правительству №10096 от 17 октября 1917 г. «Об изменении правил о поступлении на службу и определении к должностям по министерству иностранных дел» (там же: 786-788). Этот факт еще раз говорит о тех высоких требованиях, которые выдвигает дипломатическая профессия своим соискателям, и о том, что это понимали еще в предшествующие современной эпохи.

Таким образом, в 1917 г. министерство иностранных дел имело лишь один собственный вуз. В период становления Советского государства, после достаточно длительного периода фактического отрицания ведущей роли профессионализма в дипломатии, убежденности в его вторичности перед партийностью и аналогичными «революционными» псевдокатегориями, в итоге советская власть осознала важность дела подготовки кадров для внешней политики и создала слаженную систему по ее реализации, в общем и целом сущест-вующую и поныне. На благо Отечества работают Высшие курсы иностранных языков МИД РФ, Колледж МИД, знаменитая Дипломатическая академия, один из самых престижных вузов России - МГИМО (Кузнецов, 2014).

Первоистоки этих учебных заведений объективно там - в белостенных палатах, где старательно скрипели перьями «неверстанные», в неприметном питерском домике, где выводили иероглифы три актуариуса, на лекциях профессоров Шармуа и Деманжа. Все это - богатство русской дипломатии и русской культуры.

\section{СПИСОК ЛИТЕРАТУРЫ}

Васильев, Ю. А. (2006) «Кризис истории» - кризис понимания истории // Знание. Понимание. Умение. № 1. С. 35-40.

Васильев, Ю.А. (2009а) О методологических основаниях русской исторической школы: историософские аспекты. Часть I // Знание. Понимание. Умение. № 1. С. 49-58.

Васильев, Ю. А. (2009b) О методологических основаниях русской исторической школы: историософские аспекты. Часть II // Знание. Пони- 
мание. Умение. № 2. С. 78-88.

Васильев, Ю. А. (2010a) Феномен «Ecole Russe»: теория истории Н.И.Кареева (начало) // Знание. Понимание. Умение. № 2. С. 124-128.

Васильев, Ю. А. (2010b) Феномен «Ecole Russe»: теория истории Н.И.Кареева (окончание) // Знание. Понимание. Умение. № 3. С. 121-134.

Васильев Ю.А. (2011а) Идентичность русского народа в исторической концепции В. О. Ключевского // Власть. № 7. С. 35-39.

Васильев, Ю. А. (2011b) Феномен «Еcole Russe»: критика Н. И. Кареева // Знание. Понимание. Умение. № 3. С. 121-127.

Васильев, Ю. А. (2012) Феномен «Ecole russe»: историология Н. И. Кареева // Знание. Понимание. Умение. № 1. С. 72-81.

Воевода, Е. В. «Учебно-педагогическая деятельность Учебного отделения восточных языков при Азиатском департаменте МИД Российской империи» [Электронный ресурс] // МГИМО. Университет. URL: http://www. mgimo.ru/publications/?id=119896 (дата обращения 30.06.2015).

Высшее образование в России: Очерк истории до 1917 года (1995) / под ред. В. Г. Кинелева. М. : НИИ ВО. 352 с.

Зонова, Т. В. (2003) Современная модель дипломатии: истоки становления и перспективы развития. М. : РОССПЭН. 336 с.

Кузнецов, А. И. (2014) Прообразы МГИМО: из истории специального дипломатического образования в России // Вестник МГИМО Университета. № 1. С. 64-71.

Манифест от 15 декабря 1763 г. «О постановлении штатов разным Присутственным местам; об учреждении в Сенате, в Юстиции, Вотчинной и Ревизион-Коллегиях Департаментов; о разделении по оным дел; о небытии Сибирскому и Розыскному Приказам, Печатным и Раскольнической Конторам и особому Коммерц-Коллегии Комиссарству; о неимении при Присутственных местах Коллегии и Титулярных Юнкеров; об учреждении при Кадетском Сухопутном Корпусе и Московском Университете классов Российской Юриспруденции и о приготовлении детей из разночинцев и приказного чина для определения в Присутственные места в копиисты, об их обучении и содержании на казенный счет» [Электронный ресурс] // База законов. URL: http://bazazakonov.ru/doc/?ID=2749763 (дата обращения: 30.06.2015).

Министерство иностранных дел России в годы Первой мировой войны. Сборник документов (2014). Тула : Аквариус. 960 с.

Очерки истории МИД России (2002) 1802-2002 : в 3 т. М. : ОЛМАПРЕСС. Т. 3. Биографии министров иностранных дел. 1802-2002 гг. 432 с.

Похлебкин, В. В. (1992) Внешняя политика Руси, России и СССР за 1000 лет в именах, датах и фактах. Вып. І. Ведомства внешней политики и их руководители: Справочник. М. : Международные отношения. 228 с. 
Сидоров Иван Вадимович - студент факультета международных отношений, член Совета Студенческого научного общества Московского гуманитарного университета. Адрес: 111395, Россия, г. Москва, ул. Юности, д. 5, корп. В. Тел.: +7 (499) 374-75-96. Эл. адрес: nit123@yandex.ru. Научный руководитель - д-р ист. н., проф. Ю. А. Васильев.

Sidorov Ivan Vadimovich, Student, Faculty of International Relations; Member, Student Research Society, Moscow University for the Humanities. Postal address: 5 Bldg. B Yunosti St., 111395 Moscow, Russian Federation. Tel.: +7 (499) 374-75-96. E-mail: nit123@yandex.ru 